\title{
Amorphous iron phosphate: potential host for various charge carrier ions
}

\author{
Vinod Mathew ${ }^{1}$, Sungjin Kim ${ }^{1}$, Jungwon Kang ${ }^{1}$, Jihyeon Gim¹, Jinju Song ${ }^{1}$, Joseph Paul Baboo ${ }^{1}$, \\ Wangeun Park ${ }^{1}$, Docheon $\mathrm{Ahn}^{2}$, Junhee $\mathrm{Han}^{3}$, Lin $\mathrm{Gu}^{4}$, Yuesheng Wang ${ }^{4}$, Yong-Sheng $\mathrm{Hu}^{4}$, Yang-Kook Sun ${ }^{5}$ \\ and Jaekook Kim ${ }^{1}$
}

In response to the ever-increasing global demand for viable energy-storage systems, sodium and potassium batteries appear to be promising alternatives to lithium ion batteries because of the abundance, low cost and environmental benignity of sodium/ potassium. Electrical energy storage via ion-intercalation reactions in crystalline electrodes is critically dependent on the sizes of the guest ions. Herein, we report on the use of a porous amorphous iron phosphate synthesized using ambient temperature strategies as a potential host that stores electrical energy through the feasible insertion of mono-/di-/tri-valent ions. A combination of ex situ studies reveals the existence of a reversible amorphous-to-crystalline transition in this versatile electrode during electrochemical reactions with monovalent sodium, potassium and lithium. This reconstitutive reaction contributes to realizing specific capacities of 179 and $156 \mathrm{mAhg}^{-1}$ versus sodium and potassium at current densities of 10 and $5 \mathrm{mAg}^{-1}$, respectively. This finding facilitates the feasible development of several amorphous electrodes with similar phase behavior for energy-storage applications.

NPG Asia Materials (2014) 6, e138; doi:10.1038/am.2014.98; published online 17 October 2014

\section{INTRODUCTION}

Since 1990, the global demand for electricity has increased twice as much as the demand for energy overall, and the demand for electricity is expected to further increase by more than two-thirds over the next 20 years. Energy storage/conversion technologies have therefore become a crucial research topic as we seek to make society sustainable. In particular, electrical energy storage is critical not only for supporting electronic, vehicular and load-leveling applications but also for efficiently commercializing renewable solar and wind power. Rechargeable Li-ion batteries with an output energy exceeding 90\% have emerged as one of the most effective electrochemical energystorage technologies, and these batteries power most modern-day electronic devices. ${ }^{1}$ Despite substantial research to enhance Li-ion batteries for high-power applications, aspects such as their availability, cost and safety still remain to be fully addressed. ${ }^{2}$ The controversies surrounding the accessible global lithium reserves and the anticipated energy demand may greatly impact the cost of Li-ion batteries in the long term. ${ }^{3}$ Although advancing Li-ion battery technologies for electric vehicle applications is attractive, the quest for alternative energy sources for smart grid-scale storage applications has recently gained significant momentum. Rechargeable sodium and potassium batteries offer tremendous potential because they utilize inexpensive, abundant and environmentally benign sodium/potassium elements. ${ }^{4-9}$ However, the choice of ion-insertion cathodes, either crystalline or amorphous, greatly contributes to the storage/specific capacities in a typical rechargeable battery. Crystalline hosts are formed at elevated temperatures, where particle growth that is detrimental to the specific capacities is inevitable. Moreover, the storage capacities delivered by crystalline hosts are crucially dependent on various factors, including the available symmetrically/energetically equivalent sites for guest-ion occupation/transportation, crystal growth orientation and structural stability, formation of electrochemically active facets, the spatial dimension of ion migration, phase transitions and the presence of crystal imperfections/defects. Furthermore, the drastic potential drop because of the stoichiometric limitation of ion insertion and hence low ion migration at the phase-transition interface eventually lower the storage capacities in crystalline hosts. ${ }^{10}$ More importantly, hosting larger guest ions $\left(\mathrm{Na}^{+} / \mathrm{K}^{+}\right)$within the crystalline lattice may be considerably more challenging compared with that in the case of lithium. By contrast, amorphous electrodes, which possess benefits such as short-range structural ordering, improved kinetics and a high surface area and free volume to accommodate lattice distortions without producing macroscopic phase transitions, may ultimately improve specific capacities and provide stable electrochemical cycling over a wide potential window. ${ }^{11-13}$ The enhanced Gibbs free energy of formation of kinetically stable amorphous phases may facilitate

${ }^{1}$ Department of Materials Science and Engineering, Chonnam National University, Gwangju, South Korea; ${ }^{2}$ Beamline Research Division, Pohang Accelerator Laboratory, Pohang, South Korea; ${ }^{3}$ Department of Materials Science and Engineering, KAIST, Daejon, South Korea; ${ }^{4}$ Key Laboratory for Renewable Energy, Beijing National Laboratory for Condensed Matter Physics, Institute of Physics, Chinese Academy of Sciences, Beijing, China and ${ }^{5}$ Department of Energy Engineering, Hanyang University, Seoul, South Korea Correspondence: Professor J Kim, Laboratory for Energy Materials Synthesis, Department of Materials Science and Engineering, Chonnam National University, 300 Yong bong dong, Buk-gu, Gwangju 500-757, South Korea.

E-mail: jaekook@chonnam.ac.kr

Received 25 July 2014; accepted 2 September 2014 
significant enhancements in the cell potential of amorphous electrodes and thereby lead to apparently higher open circuit voltages than that in cells that utilize crystalline bulk electrodes. ${ }^{14}$ Interestingly, the short-range ordering may likely lead to an apparently greater accommodation of $\mathrm{Na} / \mathrm{K}$ ions in amorphous hosts than that found in crystalline electrodes. Although the constraints of lower ion diffusion also exist in amorphous hosts, the ion kinetics is also strongly influenced by the particle dimensions and morphologies. For example, nano-scale (typically $<100 \mathrm{~nm}$ ) particles possess a significant volume fraction of interfacial regions that provide percolation pathways for facile ion diffusion and hence contribute to realizing high specific capacities. ${ }^{15,16}$

Li-ion insertion in layered-type crystalline hosts proceeds between octahedral sites (16c) via a tetrahedral site (8a) (Figure 1). As shown in Figure 1, the trajectory of the Li-ion jumps between two adjacent $8 a$ sites lies along a $16 c$ site in spinel-type hosts. On the other hand, the Li-ion diffusion path lies along an approximate tetrahedral site between two octahedral sites in olivine-type hosts. Although apparently lower $\mathrm{Na}$-ion insertion capabilities were demonstrated in layered-type compounds, the larger size of $\mathrm{Na}^{+}(1.02 \AA)$ relative to $\mathrm{Li}^{+}(0.76 \AA)$ appears to hinder its occupation of the tetrahedral sites in the spinel/olivine structures (Figure 1). ${ }^{17-19}$ This also implies that the insertion of $\mathrm{K}$ ions $\left(\mathrm{K}^{+}-1.38 \AA\right)$ into crystalline hosts may be impractical, as shown in Figure 1. However, amorphous hosts with short-range ordering may facilitate the insertion of guest ions irrespective of their sizes (Figure 1). More importantly, amorphous electrodes prepared at low or even ambient temperatures not only preserve the active state of the constituents but also enable minimum particle growth and large-scale commercialization. Furthermore, theoretical and experimental approaches have indicated that voids formed because of nanoparticles assembled against each other can act as ionic conduits and are advantageous for ion insertion: ${ }^{20-22}$ electrolyte inundation of the pores enhances the electrode/electrolyte contact area and permits facile insertion/de-insertion of ions; improved electrode porosity promotes a desirable reduction in the overall volumetric density; and the porous framework acts as a buffer toward redundant volume expansion during ion insertion. ${ }^{23-25}$ Furthermore, electrochemically induced structural evolutions inoperando tend to enhance the storage performance of nano-scale amorphous hosts, thereby providing modular strategies toward designing improved battery electrodes. ${ }^{26}$

Herein, we report the preparation of potential amorphous metal phosphate cathodes, in particular, iron (III) phosphate with porous features, using an alcohol-assisted ambient temperature strategy. The feasibility of using this porous amorphous host to realize the insertion/ de-insertion of various carrier ions with different sizes/charges useful for energy-storage applications is also demonstrated. This amorphous host was selected because it is based on the inexpensive and environmentally benign element Fe. We used ex situ synchrotron X-ray diffraction (SXRD) and transmission electron microscopy (TEM) studies to identify a reversible transformation of this amorphous host into a crystalline structure with long-range ordering upon complete ion insertion/de-insertion. The electrochemically induced amorphous-to-crystalline reconstitutive reaction results in impressive sodium and potassium storage capacities for the amorphous $\mathrm{FePO}_{4}$. These results have implications for understanding the ion-insertion properties in a wider range of amorphous materials with similar phase behavior to realize alternative energy-storage solutions.

\section{MATERIALS AND METHODS}

\section{Materials}

Amorphous $\mathrm{FePO}_{4}$ was prepared using the starting materials iron acetate ( $\mathrm{Fe}$ $\left(\mathrm{CH}_{3} \mathrm{COO}\right)_{2}$, Sigma-Aldrich, Milwaukee, WI, USA) and phosphoric acid $\left(\mathrm{H}_{3} \mathrm{PO}_{4}\right.$, Daejung Chemicals \& Metals Co., Ltd, Shiheung-city, South Korea). An aqueous $\mathrm{Fe}$ (II) acetate solution was added to methanol to ensure that the complete hydrolysis of $\mathrm{Fe}$ (III) is prevented and that the formation of $\mathrm{Fe}^{3+}$ ions linked to hydroxyl and methyl groups occurs. An aqueous phosphoric acid solution was introduced to this solution under stirring to facilitate the precipitation of $\mathrm{FePO}_{4} \cdot \mathrm{nH}_{2} \mathrm{O}$. Once the reaction reached completion after $8 \mathrm{~h}$, the hydrated sample was vacuum-annealed at $250^{\circ} \mathrm{C}$ for $12 \mathrm{~h}$ to remove water.

\section{Powder and SXRD studies}

Powder XRD patterns were measured using a Maxima_X XRD-7000 (Shimadzu Corp, Nakagyo-Ku, Kyoto, Japan) with Ni-filtered $\mathrm{Cu}$ K $\alpha$ radiation $(\lambda=1.5406 \AA$ ) operating at $40 \mathrm{kV}$ and $30 \mathrm{~mA}$ within the scanning angle, $2 \theta$, range of $10-80^{\circ}$ in steps of $0.01^{\circ}$

Ex situ measurements were performed using SXRD at the BL442B2 beamline (in SPring-8, Hyogo, Japan), which is equipped with a large Debye-Scherrer diffractometer. After electrochemical measurements were performed until the specified number of discharge/charge cycles, the electrode samples were extracted from test coin cells for the XRD measurements. In brief, the electrodes from the lithium, sodium and potassium test cells were gently rinsed with dimethyl carbonate, propylene carbonate and ethyl methyl carbonate, respectively, to remove excess electrolyte. For the electrodes used in the sodium and potassium cells, a second washing was performed with acetonitrile. The samples were dried at room temperature in a glove-box before being separated from the stainless steel mesh, and then, the samples were stored in air-tight vials. The specimens were then sealed in glass capillaries $(0.5 \mathrm{~mm}$ diameter) for measurements. The diffraction data were obtained for the scanning angle, $2 \theta$, range of $0.01-78^{\circ}$ in steps of $0.01^{\circ}$. The incident $\mathrm{X}$-ray beam wavelength was calibrated using a $\mathrm{CeO}_{2}$ standard and fixed at 0.4996(1) $\AA$ to minimize X-ray absorption by the sample.

\section{Thermal and Mössbauer spectroscopy studies}

Thermogravimetric and differential scanning calorimetry analyses of the asprepared $\mathrm{FePO}_{4}$ powder were performed under a nitrogen atmosphere using a TGA/DTA Analyzer (SDT Q600, TA instruments, New Castle, DE, USA) from 30 to $800{ }^{\circ} \mathrm{C}$ at a heating rate of $3^{\circ} \mathrm{C} \mathrm{min}{ }^{-1}$. Mössbauer spectroscopy was performed using a conventional electromechanical-type spectrometer with the constant acceleration mode and $\mathrm{Co} / \mathrm{Rh}$-ray radiation. The maximum Doppler velocity of the driving unit was $12 \mathrm{mms}^{-1}$, and the spectrum was fitted using the least-squares method assuming a Lorentzian shape.

\section{Electron microscopy and surface area studies}

Field emission scanning electron microscopy images were obtained using a HITACHI S-4700 SEM (Tokyo, Japan) operating at $15 \mathrm{kV}$ under a low vacuum. TEM images were recorded using a FEI Tecnai F20 (Hillsboro, OR, USA) operating at $200 \mathrm{kV}$. Nitrogen adsorption measurements were performed using a Micromeritics ASAP 2020 (Norcross, GA, USA), and the surface area and pore size distributions of the sample were evaluated using the BrunauerEmmett-Teller and Barrett-Joyner-Halenda methods, respectively. Dark-field (DF) TEM images and their corresponding selected area electron diffraction (SAED) patterns were obtained using a JEM-3010 (JEOL, Tokyo, Japan) operating at $300 \mathrm{kV}$. The samples for the ex situ measurements were ground and dispersed in ethanol solvent and then transferred to a porous carbon filmsupported $\mathrm{Cu}$ mesh grid. The samples were ultrasonicated for $2 \mathrm{~h}$ to decrease agglomeration. DF-TEM images were obtained from diffracted electron beams, such as vague spots and ring patterns. Scanning TEM was performed using a JEOL $2100 \mathrm{~F}$ (JEOL).

\section{Electrochemical insertion studies}

$\mathrm{Li}^{+}, \mathrm{Na}^{+}$and $\mathrm{K}^{+}$insertion. For the electrochemical measurements, the active material was mixed with $20 \mathrm{wt} \%$ conducting carbon (Ketjen black), and 
teflonized acetylene black was used as a binder. In general, an active material loading of $2.5 \mathrm{mg} \mathrm{cm}^{-2}$ was used. The mixture was pressed onto a stainless steel mesh and dried under vacuum at $120^{\circ} \mathrm{C}$ for $12 \mathrm{~h}$, thereby forming the
$\mathrm{FePO}_{4}$ cathode. Separate 2032 coin-type lithium, sodium and potassium cells were constructed using lithium, sodium and potassium metals as the anodes, respectively. Each of these cells was fabricated by separating the common

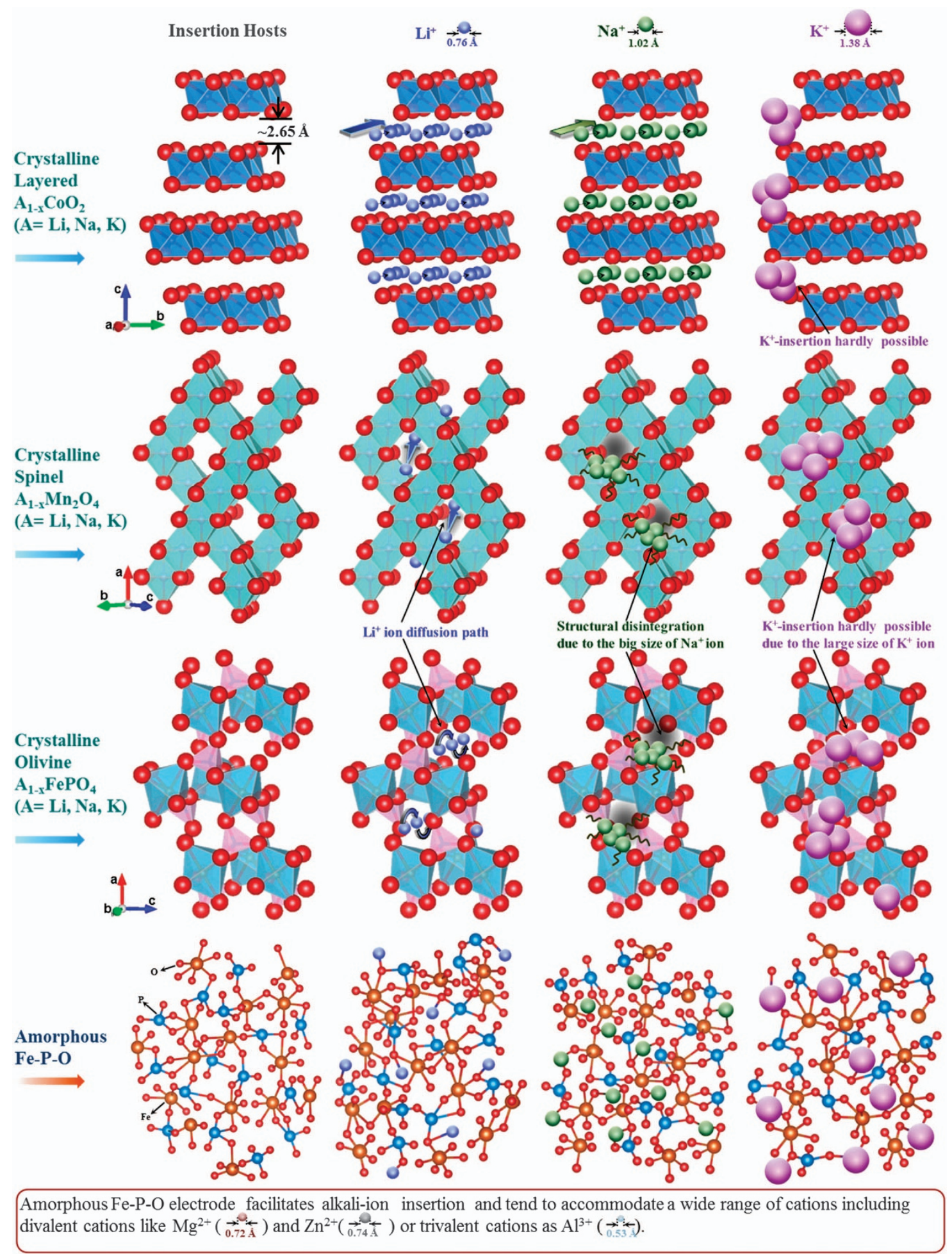

Figure 1 Schematic representation of alkali-ion insertion in crystalline and amorphous electrode hosts. The feasibility of inserting alkali ions (Li/Na/K) in crystalline (layered, spinel and olivine structured) and amorphous hosts has been presented in detail. Although the insertion of Li ions in the presented crystalline and amorphous hosts is feasible, the insertion of $\mathrm{Na}$ ions has only been demonstrated in layered-type cathodes. The feasibility of K-ion insertion in crystalline hosts is even more remote because of the relatively large size of the K-ion. The significance of amorphous hosts with short-range ordering is that these hosts facilitate the accommodation/transport of alkali ions irrespective of their sizes or possibly even charges. 
cathode from the respective anode using a glass fiber in an Ar-filled glove box and the cell was aged for $12 \mathrm{~h}$. The electrolyte employed for the lithium test cell was a 1:1 mixture of ethylene carbonate and dimethyl carbonate containing $1 \mathrm{M}$ $\mathrm{LiPF}_{6}$, whereas that used for the sodium test cell was $1 \mathrm{M} \mathrm{NaClO}_{4}$ in propylene carbonate. The potassium test cell utilized an electrolyte consisting of a 1:1 mixture of EC and ethyl methyl carbonate in $1 \mathrm{M} \mathrm{KPF}_{6}$.

$\mathrm{Zn}^{2+}$ and $\mathrm{Mg}^{2+}$ insertion. The same procedure mentioned above was used to obtain the cathodes for the zinc and magnesium test cells. For the zinc test cell, the electrolyte consisted of an aqueous solution containing $1 \mathrm{M} \mathrm{ZnSO}_{4}(\mathrm{pH}$ 4.0), and zinc metal foil was used as the anode. For the magnesium test cell, $1 \mathrm{M} \mathrm{Mg}\left(\mathrm{ClO}_{4}\right)_{2}$ dissolved in acetonitrile and magnesium ribbons were used as the electrolyte and anode, respectively. During the fabrication of the 2032-type coin cells, a Whatman glass microfiber filter (GF/B) filled with the corresponding electrolyte was sandwiched between the prepared cathode and the metallic anode. Both the coin cells were aged for $12 \mathrm{~h}$ prior to the electrochemical measurements.

$A l^{3+}$ insertion. The electrolyte used in the fabrication of the aluminum test cell was a 1:1.1 mixture of 1-ethyl-3-methylimidazolium chloride and $\mathrm{AlCl}_{3}$, and aluminum foil was used as the anode. A Whatman grade glass fiber was filled with the electrolyte and sandwiched between the cathode prepared as mentioned above and the anode in the 2032-type coin cell. The test cell was aged for $12 \mathrm{~h}$ prior to the electrochemical measurements.

The galvanostatic tests for all of these test coin cells were conducted at room temperature using a BTS 2004H (Nagano Keiki, Tokyo, Japan) in the voltage ranges of $4.2-1.6 \mathrm{~V}, 3.7-1.2 \mathrm{~V}, 3.5-1.5,1.8-0.5,1.7-0.4$ and $2.5-0.02 \mathrm{~V}$ versus $\mathrm{Li} / \mathrm{Li}^{+}, \mathrm{Na} / \mathrm{Na}^{+}, \mathrm{K} / \mathrm{K}^{+}, \mathrm{Zn} / \mathrm{Zn}^{2+}, \mathrm{Mg} / \mathrm{Mg}^{2+}$ and $\mathrm{Al} / \mathrm{Al}^{3+}$ at current densities of $20,10,4,10,5$ and $5 \mathrm{mAg}^{-1}$, respectively.

\section{Chemical insertion studies}

A sodium-biphenyl-1,2-dimethoxyethane solution was used as the sodium source for performing chemical sodiation. Appropriate amounts of starting materials, corresponding to $2 \mathrm{~mol}$ of $\mathrm{Na}$ per mol of amorphous $\mathrm{FePO}_{4}$, were weighed. Briefly, the appropriate amount of sodium, corresponding to $2 \mathrm{~mol}$, was dissolved in $10 \mathrm{ml}$ of a $1 \mathrm{~m}$ biphenyl-dimethoxyethane solution to form a dark green organic solution as the sodiating reagent. Then, the $\mathrm{FePO}_{4}$ powder was immersed into this solution and stirred until the color of the solution completely faded to obtain the sodiated samples. The final products were washed using dimethoxyethane and dried under vacuum overnight. The entire procedure was performed in an Ar-filled glove-box.

To perform chemical lithiation of amorphous $\mathrm{FePO}_{4}$, n-butyllithium was used as the lithium source. Appropriate amounts of the starting materials, corresponding to $2 \mathrm{~mol}$ of $\mathrm{Li}$ per mol of amorphous $\mathrm{FePO}_{4}$, were weighed. In brief, the $\mathrm{FePO}_{4}$ powder was mixed with n-hexane hexyl hydride, and then n-butyllithium was added dropwise while stirring to facilitate the chemical insertion of lithium. The resulting solution was stirred for 1 day, followed by filtering and washing with hexane before drying. The entire procedure was performed in an Ar-filled glove-box.

\section{RESULTS}

Nano-scale amorphous $\mathrm{FePO}_{4}$ was obtained using an ambient temperature strategy in an alcohol medium to prevent the complete hydrolysis of $\mathrm{Fe}$ and to promote alkylation. This approach, which is quite different from the usual method of using an oxidizing agent such as hydrogen peroxide in an aqueous medium, ${ }^{13}$ is explained as follows (Figure 2a). Adding the initial aqueous solution of $\mathrm{Fe}(\mathrm{II})$ acetate to methanol results in the formation of $\mathrm{Fe}^{3+}$ ions linked to hydroxyl and methyl groups, as observed by the change in the solution color from bright transparent red to dark red. The subsequent introduction of phosphoric acid thermodynamically facilitates the precipitation of $\mathrm{FePO}_{4} \cdot \mathrm{nH}_{2} \mathrm{O}$. The formation and resulting morphology of $\mathrm{FePO}_{4}$ nanoparticles are generally known to be $\mathrm{pH}$-dependent. ${ }^{22,27} \mathrm{The} \mathrm{pH}$ of the present solution was estimated to vary between 5.84 and 5.16 . The as-prepared, hydrated $\mathrm{FePO}_{4}$ was vacuum-annealed at $250{ }^{\circ} \mathrm{C}$ to obtain anhydrous $\mathrm{FePO}_{4}$. The $\mathrm{XRD}$ profiles of the as-prepared and vacuum-annealed samples (see Supplementary Figure S1) exhibit distinguishable broad reflections around the scanning angle of $2 \theta=25^{\circ}$, thereby indicating amorphous characteristics. A slight shift of the broad diffraction peak toward lower angles is observed at higher temperatures, which is most likely due to the water content in the asprepared sample. ${ }^{28}$ The thermogravimetric analysisA of the asprepared sample reveals a weight loss of $9 \mathrm{wt} \%$ (Supplementary Figure S2) until $250^{\circ} \mathrm{C}$, and no significant loss $(\sim 1.7 \mathrm{wt} \%)$ is observed between 250 and $500^{\circ} \mathrm{C}$. Additionally, it has been reported that temperatures of $200^{\circ} \mathrm{C}$ are sufficient to ensure the removal of water from hydrated iron phosphates. ${ }^{13}$ Moreover, an XRD pattern was recorded for the as-prepared sample annealed at $700{ }^{\circ} \mathrm{C}$ under an air atmosphere to empirically assess the constituent phases of the amorphous samples. This pattern exhibited sharp diffraction peaks that were well indexed to trigonal $\mathrm{FePO}_{4}$ (Supplementary Figure S1). Mossbauer analysis of the vacuum-annealed sample confirmed the presence of $\mathrm{Fe}^{3+}$ (Supplementary Figure S3), and the chemical analysis estimated the stoichiometric composition of Fe:P to be 1:1. Consequently, it is reasonable to conclude that the vacuum-annealed sample corresponds to anhydrous amorphous $\mathrm{FePO}_{4} \cdot{ }^{29}$ The FE-SEM image (Supplementary Figure S4) revealed secondary aggregates containing primary particles with diameters in the range of $20-50 \mathrm{~nm}$. The TEM images in Figures $2 \mathrm{~b}$ and $2 \mathrm{c}$ confirm the particle sizes but reveal porelike characteristics with inter-cluster voids with sizes of less than $50 \mathrm{~nm}$. The diffuse rings in the SAED pattern (Figure 2c, inset) further confirm the amorphous characteristics. To understand the porous characteristics of the amorphous $\mathrm{FePO}_{4}, \mathrm{~N}_{2}$ adsorption/desorption studies were performed. The results of these studies (Supplementary Figure S5) reveal a type-IV isotherm plot with an $\mathrm{H} 1$ hysteresis loop at a relative pressure $\left(p / p_{0}\right) \sim 0.8-1.0$. The Barrett-Joyner-Halenda poresize distribution plot (Supplementary Figure S5) peaks at $38 \mathrm{~nm}$, indicating that the prepared $\mathrm{FePO}_{4}$ possesses mesoporous characteristics. The surface area and pore volume measured at the single point of $\mathrm{P} / \mathrm{P}_{0}=0.990$ estimated by the Brunauer-Emmett-Teller studies were $91.9 \mathrm{~m}^{2} \mathrm{~g}^{-1}$ and $0.93 \mathrm{~cm}^{3} \mathrm{~g}^{-1}$, respectively. The high surface area and pore volume most likely resulted from the small-sized primary particles that aggregated to form secondary particles. ${ }^{6,22}$ Additionally, the secondary particles aggregated to form nanostructures containing inter-cluster voids (pore diameter $\sim 40 \mathrm{~nm}$ ), which are analogous to structures with mesoporous morphologies. The continuous network of particle aggregates and inter-cluster cavities promote the facile permeation of ionic moieties and enable improved electrical conductivities compared with those afforded by dispersed nanoparticles, which are loosely aggregated; hence, they serve as prospective battery cathodes for energy storage. ${ }^{30,31}$ The electrochemical capabilities of the amorphous $\mathrm{FePO}_{4}$ cathode in sodium and potassium test cells were evaluated within the potential windows of 3.7-1.2 and 3.5-1.5 V. The open circuit voltages of the $\mathrm{Na} / \mathrm{FePO}_{4}(\sim 3.05 \mathrm{~V})$ and $\mathrm{K} / \mathrm{FePO}_{4}$ $(\sim 2.64 \mathrm{~V})$ cells were found to be 500 and $800 \mathrm{mV}$ lower, respectively, than that of the $\mathrm{Li} / \mathrm{FePO}_{4}(\sim 3.45 \mathrm{~V})$ cell (see Supplementary Figure S6). In fact, theoretical studies on various sodium intercalation hosts have indicated that the battery potential is lowered by a factor of $0.18-0.57 \mathrm{~V}$ compared with that of lithium. ${ }^{9}$ When tested for its $\mathrm{Na}$-insertion properties, the $\mathrm{FePO}_{4}$ cathode delivered an initial discharge capacity of $179 \mathrm{mAhg}^{-1}$, corresponding to $100 \%$ theoretical capacity (Figure 3a). Notably, the amorphous cathode retained $97 \%$ of its theoretical capacity at the 25th cycle (Figure 3a, inset), and these values are competitive with those previously reported. ${ }^{31,32}$ More interestingly, the amorphous $\mathrm{FePO}_{4}$ delivered an initial discharge capacity of $156 \mathrm{mAhg}^{-1}$ versus potassium in the $3.5-1.5 \mathrm{~V}$ range 


\section{a}

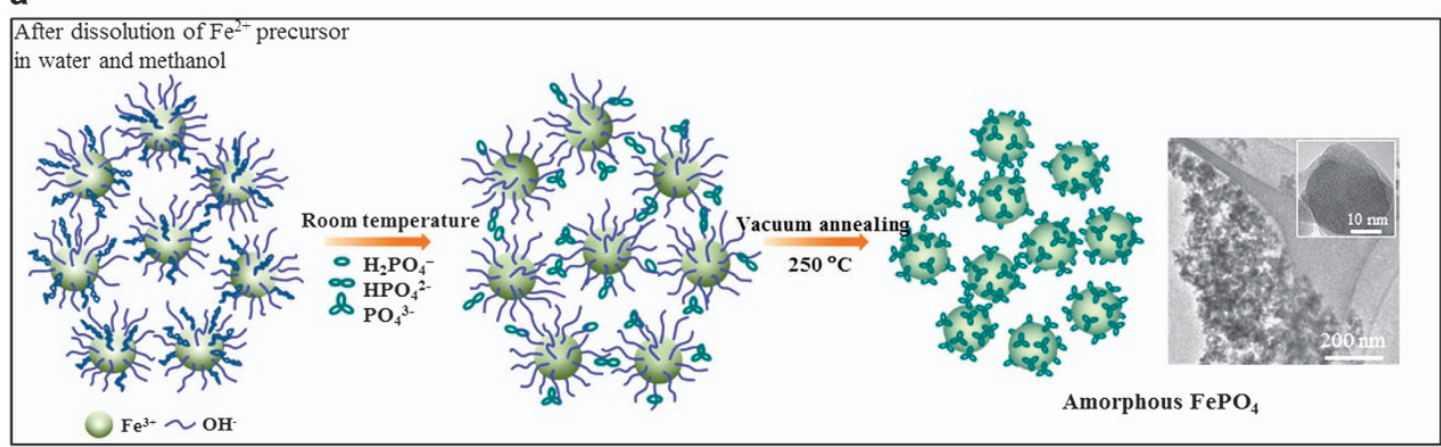

b

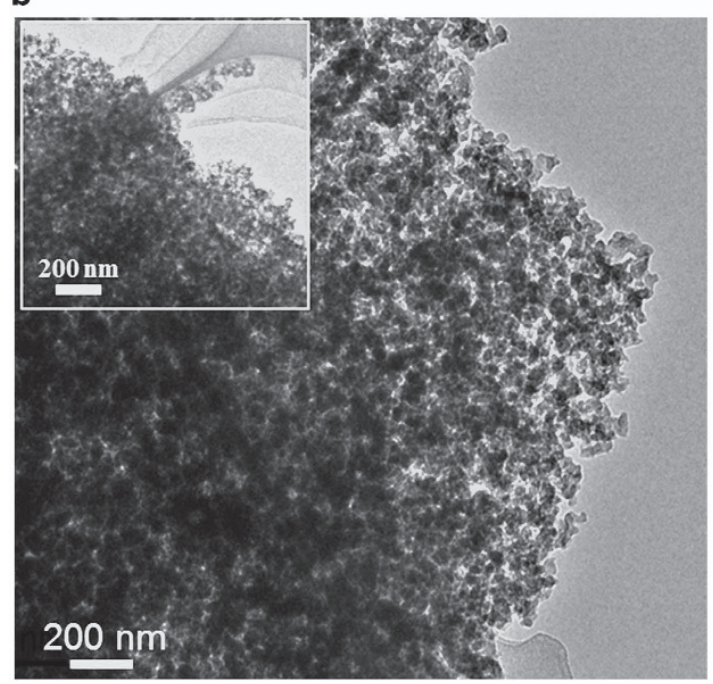

c

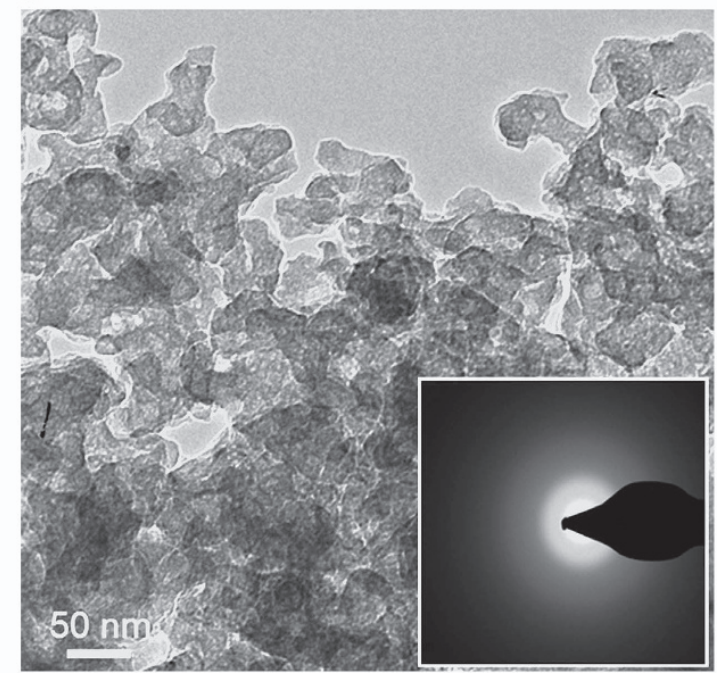

Figure 2 Schematic of amorphous $\mathrm{FePO}_{4}$ synthesis and electron microscopy studies. (a) The preparation procedure consists of the following steps. The Fe(II) precursor is dissolved in water, and the complete hydrolysis of the Fe(III) salt is prevented by the addition of alcohol to facilitate alkoxidation, as observed by the change in the solution color from bright transparent red to dark red. Introducing phosphoric acid at room temperature to the solution under stirring promotes the precipitation of hydrated phosphates. Finally, the sample is vacuum-annealed under mild temperatures $\left(250{ }^{\circ} \mathrm{C}\right)$ to obtain dehydrated amorphous phases of $\mathrm{FePO}_{4}$. The procedure can be adopted for the general synthesis of metal oxides or phosphates to develop amorphous hosts for energystorage applications. (b) TEM images of amorphous $\mathrm{FePO}_{4}$. (c) High-resolution TEM (HRTEM) image shows distinct pore-like features, and the inset shows the corresponding SAED pattern obtained using the electron diffraction technique, which confirms the amorphous nature of the $\mathrm{prepared} \mathrm{FePO}_{4}$.

(Figure $3 \mathrm{~b}$ ), and $70 \%$ of the theoretical capacity was retained until the 50th cycle (Figure 3b, inset). To the best of the authors' knowledge, this is the first report on a battery cathode with impressive performance at operating voltages of $2.5 \mathrm{~V}$ versus $\mathrm{K} / \mathrm{K}^{+} .7,8$ The apparently lower capacity, larger impedance and capacity fade during cycling of the potassium cell may be related to the apparently larger size of the $\mathrm{K}$ ion and lower ion mobility. ${ }^{33}$ The observation of a smooth slope with pseudo-plateaus at $2.5 \mathrm{~V}$ followed by a gradual potential decrease close to the lower cutoff potentials in the electrochemical profiles of the present $\mathrm{FePO}_{4}$ is unusual compared with previously reported observations. ${ }^{31,32}$ Moreover, this feature is also distinct in the voltage profile of the amorphous cathode tested versus lithium within the potential window of 4.2-1.6 V (Supplementary Figure S6). The $\mathrm{FePO}_{4}$ cathode exhibited an initial discharge capacity of $180 \mathrm{mAhg}^{-1}$, and steady capacity values with high Coulombic efficiencies were also retained until 50 electrochemical cycles (Supplementary Figure S6). Furthermore, the rate performance study indicated that the discharge capacities were 87 and $56 \mathrm{mAhg}^{-1}$ at current densities of 1000 and $2000 \mathrm{mAg}^{-1}$, respectively (Supplementary Figure S7). The delivered initial capacities are competitive with the best values that have been reported, and the marginally higher initial capacities may result from the formation of more ion migration pathways on repeated cycling. ${ }^{34,35}$

The SXRD patterns of the $\mathrm{FePO}_{4}$ cathode samples recovered from three separate sodium half-cells cycled until the completion of initial discharge, initial charge and second discharge are shown in Figure 4. Compared with the notable broad halo observed for amorphous $\mathrm{FePO}_{4}$ at $2 \theta=8^{\circ}$, the ex situ SXRD pattern after the initial $\mathrm{Na}$ insertion/sodiation (Figure 4a) reveals a broadening of the major halo and low-intensity peaks in the scanning angle (20) range of 9.3-11.4 whereas the Na-extracted/de-sodiated sample exhibits amorphous characteristics. However, the SXRD pattern of the sample recovered after two complete insertion/discharge cycles $\left(\mathrm{Na}\right.$-re-inserted $\left.\mathrm{FePO}_{4}\right)$ exhibits a protruding spike at $2 \theta=11.04^{\circ}$ that matches well with the major Bragg peak of orthorhombic $\mathrm{NaFePO}_{4}$ (JCPDS No. 89-0816, ICDD). This observation suggests that a transformation from amorphous to crystalline $\mathrm{FePO}_{4}$ likely occurs on complete $\mathrm{Na}$ insertion. However, the ex situ patterns of the Li-inserted $\mathrm{FePO}_{4}$ samples did not exhibit any marked differences in comparison with that of the Liextracted $\mathrm{FePO}_{4}$ sample (Figure $4 \mathrm{~b}$ ). Nevertheless, the phase transition is visibly evident in the ex situ patterns of the K-inserted/de-inserted $\mathrm{FePO}_{4}$ samples (Figure 4c). The SXRD pattern of the K-inserted 
$\mathrm{FePO}_{4}$ obtained after the initial discharge cycle presents distinct peaks that are well indexed to monoclinic $\mathrm{KFe}_{2}\left(\mathrm{PO}_{4}\right)_{2}$ (JCPDS No. 781176, ICDD), whereas the sample recovered after the initial charge cycle exhibits amorphous characteristics. Therefore, this observation clearly confirms the formation of a crystalline phase during $\mathrm{K}$ insertion, whereas the pristine amorphous state is retained after $\mathrm{K}$ extraction.
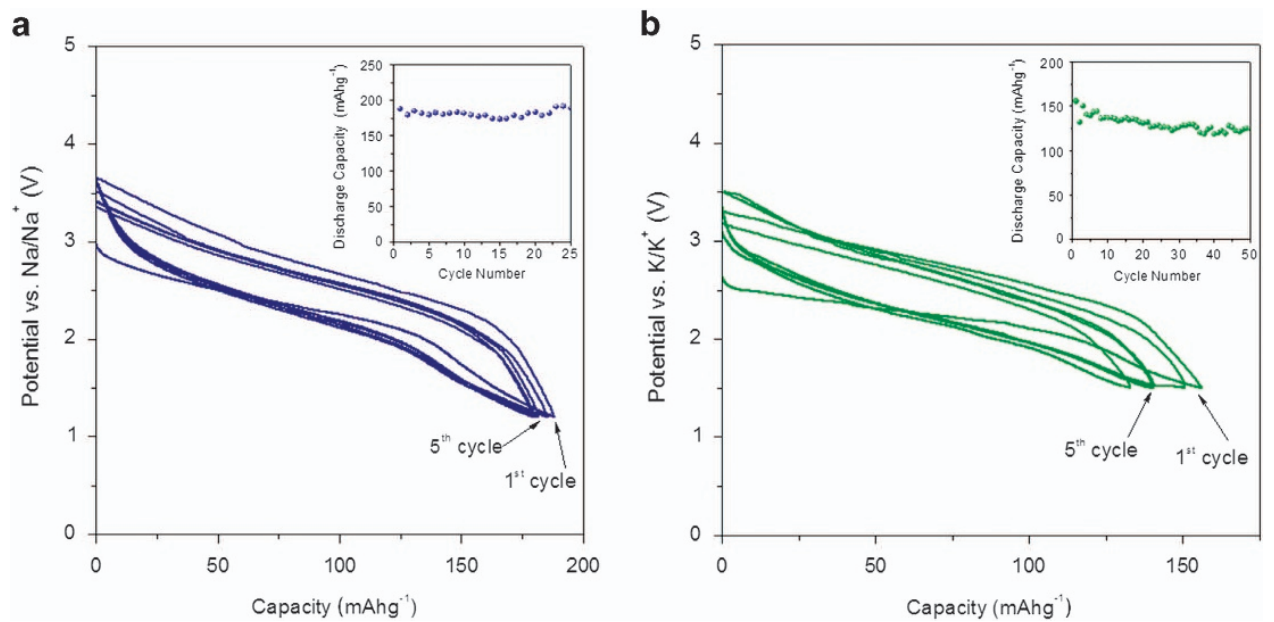

Figure 3 Electrochemical characterizations and structural characterization. The initial five voltage composition curves of the amorphous $\mathrm{FePO}_{4} \mathrm{cathode}$ in (a) sodium and (b) potassium cells cycled between 3.7-1.2 and 3.5-1.5 V at current rates of 10 and $4 \mathrm{mAg}^{-1}$ rates, respectively. Low C-rate conditions were maintained because the ionic radii of $\mathrm{Na}^{+}(1.02 \AA)$ and $\mathrm{K}^{+}(1.38 \AA)$ ions are comparatively larger than that of the usual Li ion $(0.76 \AA)$. The active material loading for all of the cells was $2.5 \mathrm{mg} \mathrm{cm}^{-2}$. The degree of impedance in the cells varies according to their respective ionic sizes in the increasing order of $\mathrm{Na}^{+}<\mathrm{K}^{+}$ions. The cycle performances of the sodium and potassium test cells are plotted as insets in (a) and (b), respectively. The sodium test cell retains nearly $100 \%$ of its discharge capacity after 25 cycles, whereas a gradual capacity fade is observed in the case of the potassium cell.
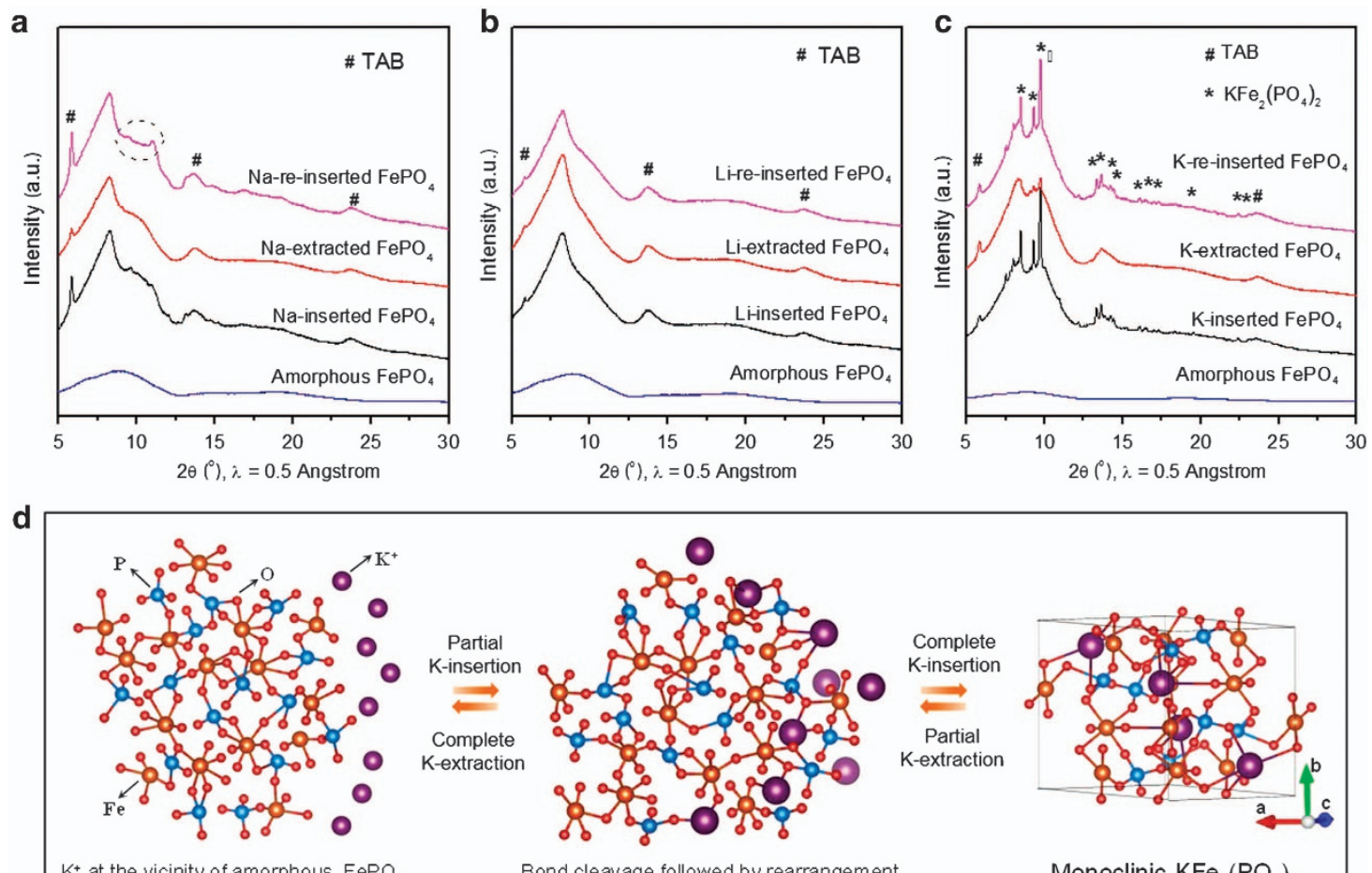

$\mathrm{K}^{+}$at the vicinity of amorphous $\mathrm{FePO}_{4}$ before electrochemical reaction.
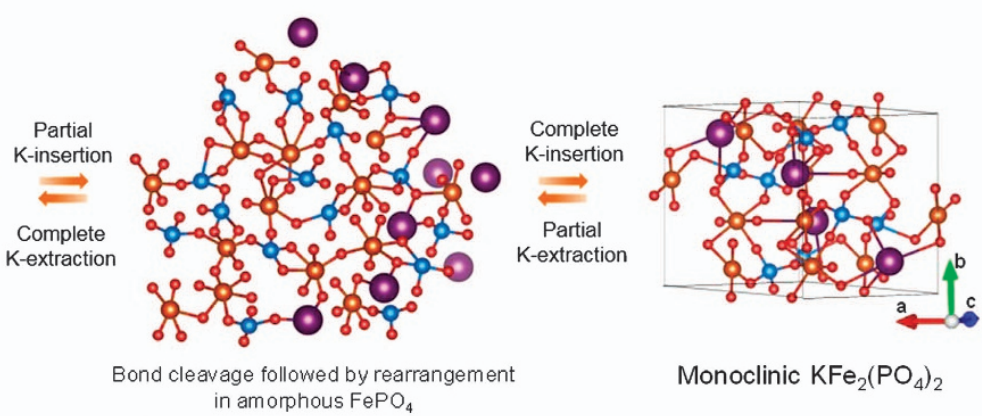

Monoclinic $\mathrm{KFe}_{2}\left(\mathrm{PO}_{4}\right)_{2}$

Figure $4 \mathrm{Ex}$ situ analysis by synchrotron X-ray diffraction (SXRD) and schematic of $\mathrm{K}$ insertion into amorphous $\mathrm{FePO}_{4}$. The black, red and magenta lines depict the SXRD patterns recorded for the ex situ electrode samples recovered from the (a) sodium, (b) lithium and (c) potassium test cells after the initial discharge, initial charge and second discharge cycles until 1.2, 3.7 and $1.2 \mathrm{~V}, 1.6,4.2$ and $1.6 \mathrm{~V}$, and $1.5,3.5$ and $1.5 \mathrm{~V}$, respectively. The blue line is the SXRD pattern of the pristine ns- $\mathrm{FePO}_{4}$ powder. The humps attributed to teflonized acetylene black used in the electrode fabrication are marked for easy identification. (d) Schematic illustration of the reversible amorphous-to-crystalline transition in amorphous $\mathrm{FePO}_{4}$ that occurs during the electrochemical $\mathrm{K}$ insertion. 
Furthermore, the re-emergence of characteristic peaks for $\mathrm{KFe}_{2}\left(\mathrm{PO}_{4}\right)_{2}$ after the second discharge cycle (K-re-inserted $\mathrm{FePO}_{4}$ ) clearly suggests that the electrochemically induced amorphous-to-crystalline transition is reversible. The crystal structure of the orthophosphate, $\mathrm{KFe}_{2}\left(\mathrm{PO}_{4}\right)_{2}$, formed after complete $\mathrm{K}$ insertion, possesses mixed Fe valence states $\left(\mathrm{Fe}^{2+} / \mathrm{Fe}^{3+}\right)$, suggesting the possibility that not all of the $\mathrm{Fe}^{3+}$ ions in the amorphous $\mathrm{FePO}_{4}$ electrode are transformed into $\mathrm{Fe}^{2+}$ ions. ${ }^{36}$ Furthermore, the formation of crystalline phases on repeated discharge cycles may also limit the possible amount of $\mathrm{K}$ that can be inserted per Fe and contribute to capacity fading during consecutive electrochemical cycling (Figure 3b, inset). Assuming that amorphous $\mathrm{FePO}_{4}$ is composed of a glassy network containing $\mathrm{Fe}-\mathrm{O}$ and $\mathrm{PO}_{4}$ units, as shown in Figure $4 \mathrm{~d}$, disruptions of the $\mathrm{Fe}-\mathrm{O}$ bonds in the amorphous electrode occur as $\mathrm{K}$ insertion proceeds within the chosen discharge potential window. As the discharge reaction concludes at $1.5 \mathrm{~V}$ (complete $\mathrm{K}$ insertion), a crystalline lattice with long-range ordering that corresponds to the monoclinic crystal system of $\mathrm{KFe}_{2}\left(\mathrm{PO}_{4}\right)_{2}$ is formed (Figure 4d). To obtain further insights into the plausible reconstitutive reaction during $\mathrm{Na} / \mathrm{Li}$ insertion, the ex situ bright- and DF-TEM images recorded for the initially sodiated and lithiated $\mathrm{FePO}_{4}$ samples are shown in Figure 5. The DF image of sodiated $\mathrm{FePO}_{4}$ (Figure $5 \mathrm{~b}$ ) reveals highly illuminated aggregates, which suggest the presence of primary crystalline particles, and the corresponding SAED pattern (Figure 5b, inset) clearly exhibits diffuse concentric rings, which is uncharacteristic of pure amorphous phases. Vague diffracted spots likely exist but are difficult to identify because of the highly intense transmission beam. Similarly, the ex situ TEM images recorded for the initially lithiated $\mathrm{FePO}_{4}$ in Figures $5 \mathrm{c}$ and $5 \mathrm{~d}$ exhibit uneven contrast primarily along the particle boundaries, which suggests the presence of tiny crystals. The corresponding SAED pattern (Figure 5d, inset) also indicates the possible existence of a crystalline phase. Therefore, the combined analysis of the ex situ SXRD and TEM results leads to the conclusion that the absence of distinguishable peaks in the SXRD patterns of the $\mathrm{Na} / \mathrm{Li}$-inserted samples is likely due to the
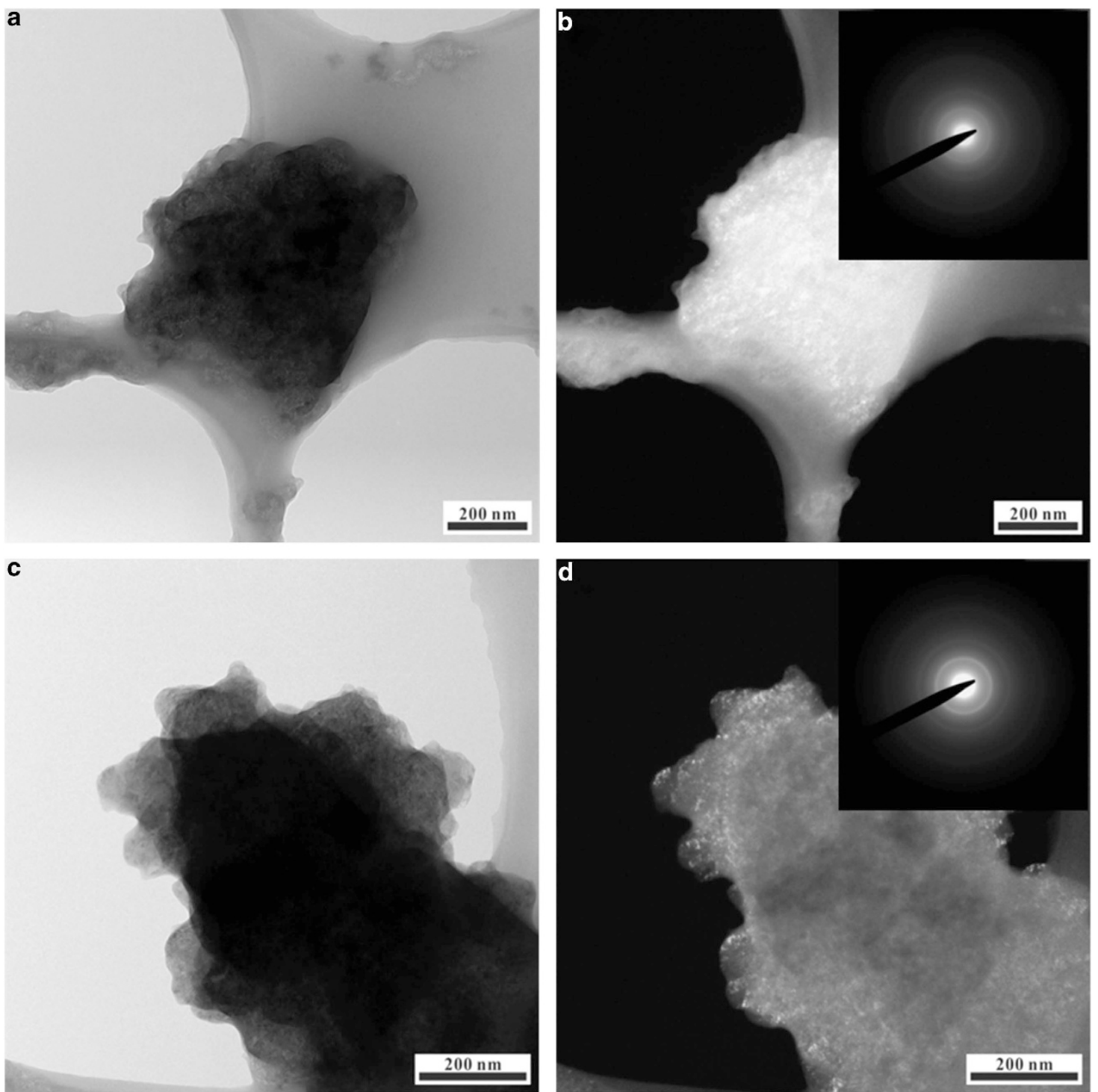

Figure 5 Ex situ TEM studies. The (a) bright- and (b) dark-field TEM images of the cathode sample extracted after one complete Na-insertion cycle. The (c) bright- and (d) dark-field TEM images of the cathode sample extracted after one complete Li-insertion cycle. The corresponding SAED patterns of the recovered cathode samples are shown in the insets of (b) and (d). 
smaller sizes of the $\mathrm{Na} / \mathrm{Li}$ ions and/or the instability of the metastable intermediate states. Precisely, the slightly larger ionic radius of the $\mathrm{Na}$ ion relative to that of the $\mathrm{Li}$ ion may contribute to the appearance of low-intensity spikes in the SXRD pattern of the Na-inserted $\mathrm{FePO}_{4}$ samples. Alternatively, the $\mathrm{K}$-inserted $\mathrm{FePO}_{4}$ sample exhibits highly crystalline diffraction peaks, most likely due to the larger size of the $\mathrm{K}$ ions. The corresponding SAED pattern (see Supplementary Figure S8) exhibits bright and distinctive spots that correspond to a $\mathrm{K}$-inserted crystalline phase, although identification of this phase is complicated. Furthermore, the energy dispersive X-ray (EDX) analysis (see Supplementary Figure S9) reveals a uniform distribution of K elements throughout the investigated area.

Chemical sodiation and lithiation were performed separately on the amorphous $\mathrm{FePO}_{4}$ (see Methods), and the scanning TEM images of the resulting samples compared with that of the pure $\mathrm{FePO}_{4}$ are presented in Figure 6. The scanning TEM image of amorphous $\mathrm{FePO}_{4}$ (Figure 6a) clearly shows no distinguishable lattice fringes, as expected, whereas the image of the chemically sodiated $\mathrm{FePO}_{4}$ (Figure 6b) reveals fringe widths with dimensions of 2.72 and $3.36 \AA$ that correspond to the (014) and (121) diffraction planes, respectively, of $\mathrm{NaFePO}_{4}$. Furthermore, the scanning TEM image of the chemically lithiated $\mathrm{FePO}_{4}$ (Figure 6c) displays fringe widths with dimensions of 2.49 and $2.38 \AA$ that correspond to the (311) and (410) diffraction planes, respectively, of $\mathrm{LiFePO}_{4}$. Therefore, the chemical $\mathrm{Na} / \mathrm{Li}$ - insertion studies also tend to support the existence of an amorphous-to-crystalline phase transition in nano-scale amorphous $\mathrm{FePO}_{4}$ cathodes with porous properties during electrochemical reactions versus sodium/potassium/lithium.

The potential of utilizing amorphous $\mathrm{FePO}_{4}$ as a divalent charge carrier was also investigated by studying $\mathrm{Zn} / \mathrm{Mg}$ insertion. The twoelectron transfer associated with the divalent charge during electrochemical reactions aids in the realization of cathodes with apparently higher energy densities. The cyclic voltammograms (Supplementary Figure S10) of amorphous $\mathrm{FePO}_{4}$ in an aqueous electrolyte medium versus a zinc metal anode within the $2-0 \mathrm{~V}$ range (see Methods) clearly reveal cathodic and corresponding anodic peaks that possibly indicate the insertion/de-insertion of $\mathrm{Zn}$ occurring across the host at room temperature. The initial discharge/charge profiles within 1.8 $0.5 \mathrm{~V}$ at a current density of $10 \mathrm{mAg}^{-1}$ (Figure 7a) indicate that the amorphous $\mathrm{FePO}_{4}$ delivered an initial discharge capacity of 96 $\mathrm{mAhg}^{-1}$ versus $\mathrm{Zn} / \mathrm{Zn}^{2+}$. Although $\mathrm{Zn}$ insertion into crystalline $\mathrm{MnO}_{2}$ hosts with tunnel-like structures has previously been reported, ${ }^{37}$ this is the first report to demonstrate $\mathrm{Zn}$ insertion in an amorphous host. Moreover, the Mg-insertion properties of amorphous $\mathrm{FePO}_{4}$ were tested in a non-aqueous electrolyte medium against a magnesium metal anode (see Methods) within the potential range of $1.7-0.4 \mathrm{~V}$ at a current density of $5 \mathrm{mAg}^{-1}$. The initial discharge/charge profile (Figure $7 \mathrm{~b}$ ) reveals that $\mathrm{FePO}_{4}$ delivered a discharge capacity of
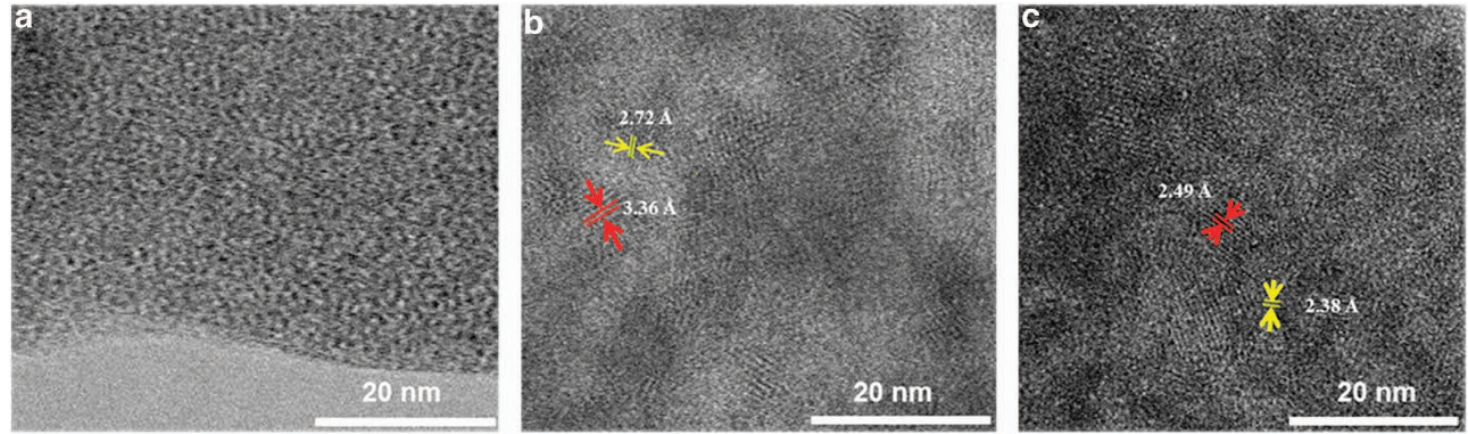

Figure 6 Scanning transmission electron microscopy (STEM) imaging studies. The STEM images obtained for (a) amorphous $\mathrm{FePO}_{4}$ showing no lattice fringes. The STEM images obtained for the (b) chemically sodiated and (c) lithiated $\mathrm{FePO}_{4}$ with their corresponding lattice fringe widths.
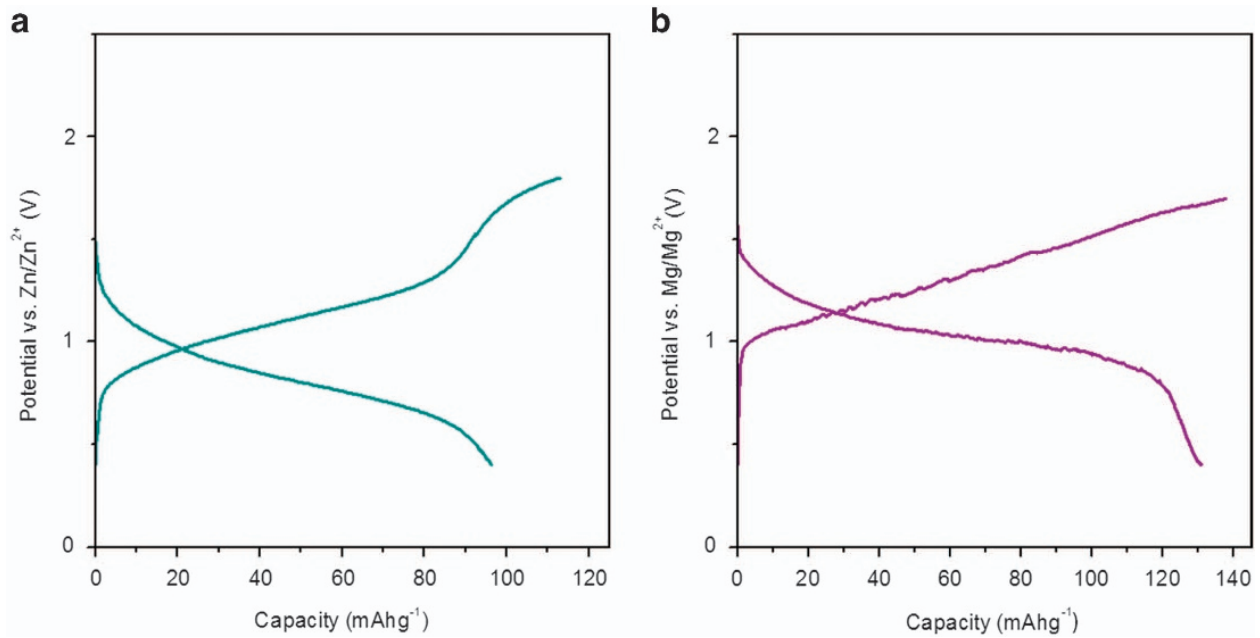

Figure 7 Electrochemical studies of $\mathrm{Zn} / \mathrm{Mg}$ insertion in amorphous $\mathrm{FePO}_{4}$. The initial voltage-capacity curves of (a) zinc and (b) magnesium cells cycled between 1.8-0.5 and 1.7-0.4 V versus zinc and magnesium under current densities of $10 \mathrm{mAg}^{-1}$ and $5 \mathrm{mAg}^{-1}$, respectively. Active material loading for the cells was $2.5 \mathrm{mg} \mathrm{cm}^{-2}$. 
$131 \mathrm{mAhg}^{-1}$ versus magnesium. Although the present performance is not superior to those reported to date, it is worth noting that the development of Mg-insertion cathodes and compatible electrolytes/ anodes remains a formidable challenge. ${ }^{18,38}$ The present $\mathrm{FePO}_{4}$ cathode was also investigated for possible $\mathrm{Al}^{3+}$ ion insertion, which is useful in aluminum-ion batteries, a prospective energy storage system that has recently gained significant research attention. ${ }^{39}$ The first two cyclic voltammograms of $\mathrm{FePO}_{4}$ (Supplementary Figure S11) against a metallic aluminum anode at room temperature in an ionic liquid-based electrolyte medium (see Methods) within $2.5-0.02 \mathrm{~V}$ exhibit cathodic $(\sim 1$ and $0.5 \mathrm{~V})$ and anodic $(\sim 0.7$ and $0.9 \mathrm{~V})$ peaks, which are most likely attributed to $\mathrm{Al}$ insertion/de-insertion into/from $\mathrm{FePO}_{4}$. The initial discharge profile of $\mathrm{FePO}_{4}$ (Supplementary Figure S11) within $1.6-0.1 \mathrm{~V}$ versus aluminum at a current density of $5 \mathrm{mAg}^{-1}$ reveals a specific capacity of $143 \mathrm{mAhg}^{-1}$. It is true that work on developing compatible/commercial electrolytes is still required to obtain a detailed understanding of the insertion/deinsertion of divalent/trivalent ions in amorphous $\mathrm{FePO}_{4}$. However, the aim of the present investigation is primarily to highlight the possibility that amorphous $\mathrm{FePO}_{4}$ cathodes with porous have considerable potential to be used as insertion hosts for a variety of ions with various sizes/charges useful in energy storage applications as rechargeable batteries.

\section{DISCUSSION}

The impressive $\mathrm{Na} / \mathrm{K}$-insertion capabilities of the amorphous $\mathrm{FePO}_{4}$ achieved under a wide potential range offer potential solutions for alternative batteries. Although sodium battery cathodes are increasingly reported, the demonstration of a prospective potassium battery cathode operating at $2.5 \mathrm{~V}$ is unique. In fact, the possibility of $\mathrm{K}$ insertion at apparently low potentials in crystalline metal-organicframework cathodes with three-dimensional porous features in an aqueous electrolyte medium was attributed to the average ion channel size being comparable with that of the solvated potassium ions. This size match facilitates rapid ion diffusion in the lattice and contributes to electrochemical reactivity over extended cycling. ${ }^{8}$ The present study, however, showcases the possibility of using amorphous $\mathrm{FePO}_{4}$ with porous morphologies formed from particle aggregates and intercluster voids as prospective host towards the reversible insertion of $\mathrm{K}, \mathrm{Na}$ and $\mathrm{Li}$ ions. Furthermore, the nano-scale particles may be advantageous for insertion/de-insertion because the high surface-tovolume ratio of nanomaterials facilitates rapid ion diffusion. The amorphous characteristics of $\mathrm{FePO}_{4}$ are represented by short-range ordering of constituents at atomic-scale lengths, and this material undergoes a transformation to a crystalline phase with a long-range ordered structure, as deduced from the high-resolution SXRD and TEM results. The electrochemically induced reversible disorder-toorder phase transition appears to contribute to the electrode performance of amorphous $\mathrm{FePO}_{4}$, and the identification of such phase transitions is familiar. ${ }^{40}$ Although the present study details the experimental observation of a unique electrochemical mechanism, the underlying factors that are responsible for this finding still require theoretical thermodynamic approaches at the nano-scale level. More importantly, the present study demonstrates the feasibility of using amorphous-based cathodes as plausible insertion hosts for divalent and trivalent ions. Furthermore, the inexpensive and simple ambient temperature strategy used to obtain this environmentally benign amorphous cathode with porous properties not only tends to simplify large-scale commercialization but also provides opportunities to develop similar transition metal-phosphate electrodes that undergo electrochemically induced reversible reconstitutive reactions for energy-storage applications.

\section{CONFLICT OF INTEREST}

The authors declare no conflict of interest.

\section{ACKNOWLEDGEMENTS}

This work was supported by the Global Frontier Program through the Global Frontier Hybrid Interface Materials (GFHIM) of the National Research Foundation of Korea (NRF) funded by the Ministry of Science, ICT \& Future Planning (2013M3A6B1078875) or (2013-073298). Technology (2009-0094055). The ex situ studies, performed using the RIKEN Beam line at SPring-8 (Japan), was supported by the Pohang Accelerator Laboratory (PAL) through the abroad beam-time program of the Synchrotron Radiation Facility Project under MEST and is gratefully acknowledged.

Author contributions: JK directed the research. VM wrote and shaped the manuscript. SK, JWK, JG, BJP, WP and VM performed experimental work and characterizations. VM, SK, YS and JG contributed to technical aspects and analysis of data. JG and JS carried out the ex situ XRD measurements. DA assisted in the ex situ XRD analysis. JH assisted in obtaining the high-resolution TEM images and SAED patterns. LG, YW and YSH performed the scanning TEM studies. All authors contributed to manuscript preparation.

1 Whittingham, M. S. Materials challenges facing electrical energy storage. MRS Bull. 33, 411-419 (2008).

2 Armand, M. \& Tarascon, J. M. Building better batteries. Nature 451, 652-657 (2008).

3 Tarascon, J. M. Is lithium the new gold? Nature Chem 2, 510-510 (2010).

4 Berthelot, R., Carlier, D. \& Delmas, C. Electrochemical investigation of the P2-Na $\mathrm{CoO}_{2}$ phase diagram. Nat. Mater. 10, 74-80 (2010).

5 Kim, D., Kang, S.-H., Slater, M., Rood, S., Vaughey, J. T., Karan, N., Balasubramaniam, M. \& Johnson, C. S. Enabling sodium batteries using lithium-substituted sodium layered transition metal oxide cathodes. Adv. Energy Mater 1, 333-336 (2011).

6 Xiong, H., Slater, M. D., Balasubramanian, M., Johnson, C. S. \& Rajh, T. Amorphous $\mathrm{TiO}_{2}$ nanotube anode for rechargeable sodium ion batteries. J. Phys. Chem. Lett. 2, 2560-2565 (2011).

7 Eftekhari, A. Potassium secondary cell based on Prussian blue cathode. J. Power Sources 126, 221-228 (2004).

8 Wessells, C. D., Peddada, S. V., Huggins, R. A. \& Cui, Y. Nickel hexacyanoferrate nanoparticle electrodes for aqueous sodium and potassium ion batteries. Nano Lett. 11, 5421-5425 (2011).

9 Ong, S. P., Chevrier, V. L., Hautier, G., Jain, A., Moore, C., Kim, S., Ma, X. \& Ceder, G. Voltage, stability and diffusion barrier differences between sodium-ion and lithium-ion intercalation materials. Energy Environ. Sci 4, 3680-3688 (2011).

10 Tang, M., Carter, W. C. \& Chiang, Y. M. Electrochemically driven phase transition in insertion electrodes for lithium-ion batteries: examples in lithium metal phosphate olivines. Ann. Rev. Mater. Res. 40, 18.1-18.29 (2010).

11 Julien, C. M. Lithium intercalated compounds-charge transfer and related properties. Mat. Sci. Eng. R 40, 47-102 (2003).

$12 \mathrm{Kim}$, J. \& Manthiram, A. A manganese oxyiodide cathode for rechargeable lithium batteries. Nature 390, 265-267 (1997).

13 Prosini, P. P., Lisi, M., Scaccia, S., Carewska, M., Cardellini, F. \& Pasquali, M. Synthesis and characterization of amorphous hydrated $\mathrm{FePO}_{4}$ and its electrode performance in lithium batteries. J. Electrochem. Soc. 149, A297-A301 (2002).

14 Delmer, O., Balaya, P., Kienle, L. \& Maier, J. Enhanced potential of amorphous electrode materials: Case study of $\mathrm{RuO}_{2}$. Adv. Mater. 20, 501-505 (2008).

15 Heitjans, P. \& Indris, S. Diffusion and ionic conduction in nanocrystalline ceramics. J. Phys.: Condens. Matter 15, R1257-R1289 (2003).

16 Borghols, W. J. H., Lutzenkirchen-Hecht, D., Haake, U., Chan, W., Lafont, U., Kelder, E. M., Van eck, E. R. H., Kentgens, A. P. M., Mulder, F. M. \& Wagemaker, M. Lithium storage in amorphous $\mathrm{TiO}_{2}$ nanoparticles. J. Electrochem. Soc. 157, A582-A588 (2010).

17 Delmas, C., Nadiri, A. \& Soubeyroux, J. L. The NASICON-type titanium phosphates ATi $\left(\mathrm{PO}_{4}\right)_{3}(\mathrm{~A}=\mathrm{Li}, \mathrm{Na})$ as electrode materials. Solid State lonics 28-30, 419-423 (1988).

18 Spahr, M. E., Novak, P., Haas, O. \& Nesper, R. Electrochemical insertion of lithium, sodium and magnesium in molybdenum (VI) oxide. J. Power Sources 54, 346-351 (1995).

19 Tang, P. E., Sakamoto, J. S., Baudrin, E. \& Dunn, B. $\mathrm{V}_{2} \mathrm{O}_{5}$ aerogel as a versatile host for metal ions. J. Non-cryst. Solids 350, 67-72 (2004).

20 Divinski, S. V. \& Larikov, L. N. Diffusion in nanostructured materials. Defect Diffus. Forum 143-147, 1469-1474 (1997).

21 Kaneko, K. Determination of pore size and pore size distribution 1. Adsorbents and catalysts. J. Membrane Sci. 96, 59-89 (1994).

22 Kandori, K., Kuwae, T. \& Ishikawa, T. Control on size and adsorptive properties of spherical ferric phosphate particles. J. Colloid Interface Sci. 300, 225-231 (2006). 
23 Jiao, F., Shaju, K. M. \& Bruce, P. G. Synthesis of nanowire and mesoporous lowtemperature $\mathrm{LiCoO}_{2}$ by a post-templating reaction. Angew. Chem. Int. Ed. 44, 550-553 (2005).

24 Mathew, V., Lim, J., Kang, J., Gim, J., Rai, A. K. \& Kim, J. Self-assembled mesoporous manganese oxide with high surface area by ambient temperature synthesis and its enhanced electrochemical properties. Electrochem. Commun. 13, 730-733 (2011).

25 Szeifert, J. M., Feckl, J. M., Rohlfing, D. F., Liu, Y., Kalousek, V., Rathousky, J. \& Bein, T. Ultrasmall titania nanocrystals and their direct assembly into mesoporous structures showing fast lithium insertion. J. Am. Chem. Soc 132, 12605-12611 (2010).

26 Xiong, H., Yildirim, H., Shevchenko, E. V., Prakapenka, V. B., Koo, B., Slater, M. D., Balasubramaniam, M., Sankaranarayanan, S. K. R. S., Greeley, J. P., Tepavcevic, S., Dimitrijevic, N. M., Podasilado, P., Johnson, C. S. \& Rajh, T. Self-improving anode for lithium-ion batteries based on amorphous to cubic phase transition in $\mathrm{TiO}_{2}$ nanotubes. J. Phys. Chem. C 116, 3181-3187 (2012).

27 Yang, H. J., Song, H. J., Shin, H. J. \& Choi, H. C. A rapid synthesis of iron phosphate nanoparticles via surface-mediated spontaneous reaction for the growth of high-yield, single-walled carbon nanotubes. Langmuir 21, 9098-9102 (2005).

28 Hong, Y.-S., Ryu, K. S., Park, Y. J., Kim, M. G., Lee, J. M. \& Chang, S. H. Amorphous $\mathrm{FePO}_{4}$ as $3 \mathrm{~V}$ cathode material for lithium secondary batteries. J. Mater. Chem. 12, 1870-1874 (2002)

29 Yang, S., Song, Y., Zavalij, P. Y. \& Whittingham, M. S. Reactivity, stability and electrochemical behavior of lithium iron phosphates. Electrochem. Commun. 4, 239-244 (2002).

30 Holland, B. T., Blanford, C. F., Do, T. \& Stein, A. Synthesis of highly ordered, threedimensional, macroporous structures of amorphous or crystalline inorganic oxides, phosphates, and hybrid composites. Chem. Mater. 11, 795-805 (1999).

31 Liu, Y., Xu, Y., Han, X., Pellegrinelli, C., Zhu, Y., Zhu, H., Wan, J., Chung, A. C., Vaaland, O., Wang, C. \& Hu, L. Porous amorphous $\mathrm{FePO}_{4}$ nanoparticles connected by single-wall carbon nanotubes for sodium ion battery cathodes. Nano Lett. 12, 5664-5668 (2012).

32 Fan, Q., Lei, L., Yin, G., Chen, Y. \& Sun, Y. Direct growth of $\mathrm{FePO}_{4} /$ graphene hybrids for Li-ion and Na-ion storage. Electrochem. Commun. 38, 120-123 (2014).

33 Moore, J. W., Stanitski, C. L. \& Jurs, P. C. Chemistry: The Molecular Science 1st Edition, Harcourt College Publishers: Texas, (2002) -Korean version.
34 Lee, Y. J., Yi, H., Kim, W.-J., Kang, K., Yun, D. S., Strano, M. S., Ceder, G. \& Belcher A. M. Fabricating genetically engineered high-power Lithium-ion batteries using multiple virus genes. Science 324, 1051-1055 (2009).

35 Kim, S. W., Ryu, J., Park, C. B. \& Kang, K. Carbon nanotube-amorphous $\mathrm{FePO}_{4}$ coreshell nanowires as cathode material for $\mathrm{Li}$ ion batteries. Chem. Commun. 46 7409-7411 (2010).

36 Yakubovich, O.V., Evdokimova, O.A., Mel'nikov, O.K. \& Simonov, M. A. Crystal structure of a new $\mathrm{K}, \mathrm{Fe}$ orthophosphate, $\mathrm{KFe}^{2+} \mathrm{Fe}^{3+}\left(\mathrm{PO}_{4}\right)_{2}$. Homeotypism structures of $\mathrm{KFe}^{2+} \mathrm{Fe}^{3}$ $+\left(\mathrm{PO}_{4}\right)_{2}$ and $\mathrm{Fe}^{32+}\left(\mathrm{H}_{2} \mathrm{O}\right)\left(\mathrm{PO}_{4}\right)_{2}{ }^{\prime \prime}$. Kristallografiya 31, 906-912; Sov. Phys. Crystallogr (Engl. Transl.) 31, 537-541 (1986).

$37 \mathrm{Xu}, \mathrm{C} ., \mathrm{Li}, \mathrm{B} ., \mathrm{Du}, \mathrm{H}$. \& Kang, F. Energetic zinc ion chemistry: The rechargeable zinc ion battery. Angew. Chem. Int. Ed. 51, 933-935 (2012).

38 Levi, E., Gofer, Y. \& Aurbach, D. On the way to rechargeable Mg batteries: The challenge of new cathode materials. Chem. Mater. 22, 860-868 (2010).

39 Jayaprakash, N., Das, S. K. \& Archer, L. A. The rechargeable aluminum-ion battery. Chem. Comm 47, 12610-12612 (2011).

40 Crosnier, O., Mounsey, C., Herle, P. S., Taylor, N. \& Nazar, L. F. Crystal structure and electrochemical behavior of $\mathrm{Li}_{2} \mathrm{CuP}$ : a surprising reversible crystalline-amorphous transformation. Chem. Mater. 15, 4890-4892 (2003).

(c) (1) $($ ) This work is licensed under a Creative Commons Attribution-NonCommercial-NoDerivatives 4.0 International License. The images or other third party material in this article are included in the article's Creative Commons license, unless indicated otherwise in the credit line; if the material is not included under the Creative Commons license, users will need to obtain permission from the license holder to reproduce the material. To view a copy of this license, visit http://creativecommons.org/licenses/ by-nc-nd/4.0/

Supplementary Information accompanies the paper on the NPG Asia Materials website (http://www.nature.com/am) 


\section{Amorphous iron phosphate: potential host for various charge carrier ions}

Vinod Mathew, Sungjin Kim, Jungwon Kang, Jihyeon Gim, Jinju Song, Joseph Paul Baboo, Wangeun Park, Docheon Ahn, Junhee Han, Lin Gu, Yuesheng Wang, Yong-Sheng Hu, Yang-Kook Sun and Jaekook Kim

NPG Asia Materials (2015) 7, e149; doi:10.1038/am.2014.118; published online 9 January 2015

Correction to: NPG Asia Materials (2014) 6, e138; doi:10.1038/ am.2014.98; published online 17 October 2014

After the online publication of this article, the authors noticed an error in the Acknowledgements section.

The correct statements in the Acknowledgements section of this article should have read as below.

This work was supported by the Global Frontier Program through the Global Frontier Hybrid Interface Materials (GFHIM) of the
National Research Foundation of Korea (NRF) funded by the Ministry of Science, ICT \& Future Planning (2013M3A6B1078875) or (2013-073298). The ex situ studies, performed using the RIKEN Beam line at Spring-8 (Japan), was supported by the Pohang Accelerator Laboratory (PAL) through the abroad beam-time program of the Synchrotron Radiation Facility Project under MEST and is gratefully acknowledged.

The authors apologize for the error. 